\title{
BMJ Open Anticoagulation adherence and its associated factors in patients with atrial fibrillation: a cross-sectional study
}

\author{
Pei-Ti Chen, ${ }^{1}$ Tsae-Jyy Wang, ${ }^{\circ}$ Ming-Hsiung Hsieh, ${ }^{3}$ Ju-Chi Liu, ${ }^{4}$ Chieh-Yu Liu, ${ }^{5}$ \\ Kwua-Yun Wang, ${ }^{6}$ Wen-Chun Laio ${ }^{7}$
}

To cite: Chen P-T,

Wang T-J, Hsieh M-H, et al. Anticoagulation adherence and its associated factors in patients with atrial fibrillation: a cross-sectional study. BMJ Open 2019;9:e029974. doi:10.1136/ bmjopen-2019-029974

- Prepublication history for this paper is available online. To view these files please visit the journal online (http://dx.doi org/10.1136/bmjopen-2019029974).

Received 20 February 2019 Revised 01 August 2019 Accepted 12 August 2019

\section{Check for updates}

(C) Author(s) (or their employer(s)) 2019. Re-use permitted under CC BY-NC. No commercial re-use. See rights and permissions. Published by BMJ.

${ }^{1}$ Nursing, Cardinal Tien Junior College of Healthcare and Management, Taipei, Taiwan ${ }^{2}$ Nursing, National Taipei University of Nursing and Health Sciences, Taipei, Taiwan

${ }^{3}$ Cardiology, Taipei Medical University, Taipei, Taiwan ${ }^{4}$ Internal Medicine, Taipei Medical University Shuang Ho Hospital, New Taipei City, Taiwan ${ }^{5}$ Speech Language Pathology and Audiology, National Taipei University of Nursing and Health Sciences, Taipei, Taiwan

${ }^{6}$ Nursing, National Defense Medical Center, Taipei, Taiwan ${ }^{7}$ Nursing, China Medical University, Taichung, Taiwan

Correspondence to Dr Tsae-Jyy Wang; tsaejyy@ntunhs.edu.tw

\section{ABSTRACT}

Objective To investigate anticoagulant adherence and its associated factors, including demographics, clinical variables, atrial fibrillation (AF) severity, knowledge, satisfaction with services, perceived barriers, perceived benefits, symptom severity and self-efficacy in patients with AF.

Design This is a cross-sectional study.

Participants and setting A convenient sample of patients with AF were recruited from cardiology clinics of two teaching hospitals in Taiwan.

Measures Data were collected using the study questionnaires, including the AF-related symptom subscale of the AF Severity Scale, the Knowledge of Warfarin Anticoagulation Treatment Scale, the Satisfaction Scale about Service and Warfarin Treatment, the perceived benefits subscale of the Beliefs about Anticoagulation Survey, the Concerns about Anticoagulation Therapy Scale, The Self-efficacy for Appropriate Medication Use Scale and the short-form Adherence to Refills and Medications Scale. Results A total of 151 patients with AF participated in the study; 53 treated with warfarin and 98 treated with novel oral anticoagulants (NOACs). The difference in adherence to warfarin (mean=8.6; $\mathrm{SD}=1.6$ ) and NOACs (mean=8.9; $\mathrm{SD}=2.0$ ) was statistically insignificant. Multiple linear regression analysis showed that perceived barriers $(\beta=0.18, p=0.017)$ and self-efficacy $(\beta=-0.48, p<0.001)$ were significant predictors of anticoagulation adherence. For every 1-unit increase in the perceived barriers, there will be a 0.18-unit increase in the adherence to anticoagulation therapy. For every 1 -unit increase in the self-efficacy, there will be a 0.48 -unit decrease in the adherence to anticoagulation therapy. Perceived barriers and self-efficacy collectively explained $34.0 \%$ of the variance in adherence to anticoagulation therapy $\left(F_{(2,149)}=38.11, p<0.001\right)$.

Conclusion We found no better adherence to NOACs compared with warfarin. Patients with greater self-efficacy and perceived fewer barriers showed better adherence to anticoagulation therapy.

\section{INTRODUCTION}

Atrial fibrillation (AF) is the most common type of arrhythmia. ${ }^{1-3}$ AF associated haemodynamic changes and thrombosis increases risks of heart failure, stroke and sudden death. ${ }^{4}$ In Taiwan, patients with $\mathrm{AF}$ are

\section{Strengths and limitations of this study}

This is one of the few studies that compared medication adherence between patients taking warfarin and novel oral anticoagulants.

- The cross-sectional nature of the study precluded an assessment of medication adherence change over time and did not permit us to determine causal relationships among the study variables.

> A self-report questionnaire was used to measure medication adherence, which was subject to recall and social desirability biases.

fivefold more likely to have a stroke than the general population, whereas one in five patients with stroke has AF. ${ }^{5}$ Moreover, $46.2 \%$ of patients with AF have an ischaemic stroke within 3 years of diagnosis. ${ }^{6}$ Anticoagulation treatment is the most important measure for preventing stroke in patients with $\mathrm{AF}^{1-3}$ However, inadequate anticoagulation use is a global problem. ${ }^{78}$ In Taiwan, while $90 \%$ of patients with AF meet the criteria for anticoagulation treatment, only $28.28 \%$ use it. ${ }^{9}$ Correlation studies on AF and stroke show that 185570 cases of stroke occur each year in patients with $\mathrm{AF}$ with no antiplatelet or oral anticoagulation treatment. ${ }^{10}$

Vitamin $\mathrm{K}$ antagonists (VKAs) such as warfarin and novel oral anticoagulants (NOACs) are the two main types of anticoagulants currently used for patients with $\mathrm{AF}^{1-3}$ While using warfarin, the international normalised ratio (INR) must be closely monitored as warfarin tends to interact with other drugs or foods, and it is difficult to maintain the percentage of time in the therapeutic range. ${ }^{3}$ NOACs should be used if INR is difficult to maintain in the desired therapeutic range while using warfarin. ${ }^{2}$ Lin et $a l^{11}$ found that it is difficult to choose an optimal dose of warfarin in Asian populations because of substantial variation in the individual response to warfarin and the narrow 
therapeutic range. Chiang et $a l^{1}$ also found that warfarin significantly increases the risk of intracranial haemorrhage and recommended NOACs as the preferred treatment in Asian populations with AF. However, warfarin is still the most common and widely used anticoagulant for patients with AF in Taiwan. ${ }^{11}$

Good anticoagulant adherence ensures medication safety and effective prevention of stroke. Low adherence is associated with higher mortality and morbidity of cardiovascular diseases. ${ }^{12}$ Knowing factors that affect anticoagulant adherence will help identify the populations at risk for non-adherence and allow for the development of appropriate measures to improve medication adherence. Previous studies showed that low adherence was related to (1) concerns about adverse drug reactions $^{13}$; (2) inadequate knowledge of $\mathrm{AF}$ associated risks for stroke ${ }^{13} ;(3)$ unawareness of the importance of medication adherence $^{13} ;(4)$ symptom severity ${ }^{13} ;(5)$ fear of regular blood tests ${ }^{13}$; (6) inability to attend frequent clinical visits ${ }^{14}$; (7) undergoing invasive treatments or procedures ${ }^{13}$ and (8) comorbidities. ${ }^{14}$ However, most of these studies were conducted in Western Caucasian populations and in patients taking warfarin. Whether patients from different cultural backgrounds share similar factors deserve further investigations. Additionally, few studies have investigated the differences in medication adherence for taking NOACs versus warfarin in patients with $\mathrm{AF}$, and they have yielded inconsistent results. Yao $e t \mathrm{al}^{15}$ conducted a retrospective cohort analysis to investigate adherence to oral anticoagulants in patients with $\mathrm{AF}$, wherein the proportion of days covered (PDC) $\geq 80 \%$ indicated good adherence. The overall PDC was $47.5 \%$ for NOACs (dabigatran, rivaroxaban and apixaban) and $38.7 \%$ for warfarin $(\mathrm{p}<0.001)$, indicating better adherence to NOACs than to warfarin. Choi et $a l^{16}$ analysed $364 \mathrm{AF}$ cases (warfarin: $\mathrm{n}=204$, dabigatran: $\mathrm{n}=160$ ) and assessed medication adherence with missed doses per month. The data showed that an average of 0.65 dabigatran tablets and an average of 0.63 warfarin tablets were missed per month $(\mathrm{p}=0.916)$. The results from the above studies show that medication adherence varies with each NOACs, which is not always superior to that of warfarin.

Therefore, the purposes of this study were to (1) compare the differences in adherence between patients treated with warfarin and NOACs; (2) explore factors influencing anticoagulant adherence in patients with $\mathrm{AF}$, including demographics, clinical variables (disease duration, stroke risk assessment, bleeding risk assessment, anticoagulation therapies and adverse reactions), AF severity, anticoagulation treatment knowledge, satisfaction with services, beliefs about anticoagulation treatment and self-efficacy for appropriate medication and (3) investigate the important predictors of anticoagulant adherence in patients with AF.

\section{METHODS}

\section{Study design}

This is a cross-sectional study. Data were collected with self-reported questionnaires.

\section{Participants and setting}

Patients with AF who met the following eligibility criteria were recruited from cardiology outpatient clinics of two teaching hospitals in Taipei, Taiwan. The inclusion criteria were (1) $\geq 20$ years of age; (2) fluent in Mandarin or Taiwanese; (3) diagnosed with AF and (4) treated with warfarin or NOACs for anticoagulation. The exclusion criteria were (1) diagnosed with psychological diseases; (2) diagnosed with uncontrolled hypertension; (3) diagnosed with the New York Heart Association grade VI heart failure; (4) implanted with a cardiac pacemaker; (5) had a cardiac surgery in the past 3 months and (6) hospitalised for $\mathrm{AF}$ in the past 3 months. The desired sample size was estimated by using the G power V.3.1 software. In consideration of the number of potential predictors $(n=17)$ in this study, a sample size of 146 would have $80 \%$ power to detect a medium effect size of $\mathrm{f}^{2}=0.15$ with a 0.05 level of significance using a multiple linear regression fixed model. The use of NOACs or warfarin was treated as a single variable for the sample size calculation.

\section{Patient and public involvement}

The development of the research hypothesis was informed by working closely with patients with AF. However, patients and the public were not involved in the recruitment process and conduct of the study. An abstract of the study results will be mailed to the study participants.

\section{Data collection}

The investigator administered the study questionnaire after obtaining informed consent from each subject. The data collection took place in the waiting areas outside the outpatient clinics during the patients' visits to the clinics. For subjects who were unable to read the questionnaire due to vision or other problems, the investigator read each question to help them complete the questionnaire.

\section{Variables and measurements}

Sociodemographics were provided by the subjects, including age, sex, education level, marital status and employment status. Data on clinical variables were extracted from the participants' medical records, including disease duration, $\mathrm{CHA}_{2} \mathrm{DS}_{2}$-VASc score for stroke risk assessment, HAS-BLED score for bleeding risk assessment and anticoagulation therapies (name of the medication and dosing frequency). The subjects were also asked to report anticoagulant-related adverse reactions, including bleeding events, hypersensitivity, gastrointestinal reactions, dizziness, headache, fainting, limb pain and oedema.

The AF related symptom subscale of the AF Severity Scale $(\mathrm{AFSS})^{17}$ was used to measure symptom severity. The seven-item subscale covers seven AF-related symptoms. For each item, the subjects indicated how often 
within the last month they experienced the symptom on a 6-point Likert scale (from 0 -I have not had this symptom in the past 4 weeks to $5-$ a great deal). The total score of the seven items represents the scale score, with a possible range of 0 to 35. Higher scores indicate higher levels of symptom severity. The scale has shown an acceptable level of reliability and validity in past studies involving patients with AF. ${ }^{18}$ This English scale was translated into Chinese through the following steps: Chinese translation, synthesis, back translation, expert committee review and pilot testing. ${ }^{19}$ Its Content Validity Index (CVI) was greater than 0.9 , indicating good expert validity ${ }^{19}$ In this study, Cronbach's $\alpha$ value was 0.80. A high Cronbach's $\alpha$ coefficient $(\mathrm{eg},>0.8)$ indicates good internal consistency reliability. ${ }^{20}$

The Chinese version of Knowledge of Warfarin Anticoagulation Treatment Scale ${ }^{21}$ was used to measure warfarin treatment knowledge. The 11-item scale covers four areas of warfarin treatment knowledge: administration (eg, dose, colour and route of administration), interaction with foods, interaction with other drugs and side effects. There are five choices for each item, and only one of the choices is correct (scored 1). The total score of the 11 items represents the scale score, with a possible range of $0-11$. Higher scores indicate higher levels of understanding of warfarin treatment. The scale was also modified to measure NOACs treatment knowledge. The item 1 (regarding anticoagulant dosage) in the original scale was revised into two items, one for dosage and one for the name of the medication in the NOACs knowledge scale. The item 2 (regarding INR) in the original scale was deleted. The item 4 (regarding how to make up the missing dose) was revised into two items, one for missing a dose in taking NOACs once a day and one for missing a dose in taking NOACs twice a day. The total score of the 13 items represents NOACs treatment knowledge. The potential scores range from 0 to 12 , with higher scores indicating higher levels of understanding of NOACs treatment. To facilitate analysis and comparison, the score of each scale was converted to a scale of 0 to 100 (actual score/possible maximum score $\times 100$ ). The knowledge of warfarin anticoagulation treatment scale has shown good psychometric properties in a previous study involving patients treated with anticoagulants. ${ }^{21}$ In the current study, Kuder-Richardson Formula 20 (KR-20) was 0.68 for warfarin treatment knowledge and 0.63 for NOACs treatment knowledge. The KR-20 is a measure of internal consistency reliability for dichotomous scale items.

The Chinese version of Satisfaction Scale about Service and Warfarin Treatment $(\mathrm{SSWT})^{19}$ was used to measure subjects' satisfaction with services and anticoagulation treatment provided by the healthcare team. The original scale includes seven positive statements about the services and warfarin treatment. In the current study, the term warfarin was replaced with anticoagulants. The item 5 (regarding INR monitoring) in the original scale was deleted as it only applies to patients treated with warfarin. Therefore, there were only six items used in the current study. For each item, the subjects indicated their levels of agreement on a 5-point Likert scale (from 0-strongly disagree to 4-strongly agree). The total score of the six items represents the scale score, with a possible range of 0-24. Higher scores indicate higher levels of satisfaction about service and warfarin treatment. The scale has shown good psychometric properties in a previous study involving patients treated with anticoagulants. ${ }^{21}$ In this study, Cronbach's $\alpha$ was 0.87 .

The perceived benefits subscale of the Beliefs about Anticoagulation Survey (BAAS) ${ }^{22}$ was used to measure subjects' perceived benefits associated with taking anticoagulants. The subscale covers five potential benefits of taking anticoagulation, including lessening the risk of having a stroke, lowering the chance of being hospitalised, feeling healthier, improving quality of life and worrying less about the disease. For each item, the subjects indicated their levels of agreement on a 5-point Likert scale (from 1-strongly disagree to 5-strongly agree). The potential scores range from 5 to 25 , with higher scores indicating higher levels of perceived benefits associated with taking anticoagulation. The scale has shown reasonable psychometric properties in a previous study involving patients treated with anticoagulation. ${ }^{22}$ The scale was translated into Chinese by our research team following the same steps as described prior. Its CVI was 1.0 and Cronbach's $\alpha$ was 0.84 .

The Chinese version of the Concerns about Anticoagulation Therapy Scale ${ }^{19}$ was used to measure perceived barriers regarding anticoagulation treatment. The scale lists 10 potential concerns, including drug interactions, forgetting to take anticoagulants, side effects, hospital visits, diet interactions, activity restrictions, impact on work, not helpful and difficulty of following instructions.

\begin{tabular}{|c|c|c|c|}
\hline Variables & Mean & SD & Range \\
\hline Age & 72.0 & 8.6 & $55-93$ \\
\hline Disease duration (month) & 74.0 & 61.1 & 2-389 \\
\hline Symptom severity & 6.8 & 5.4 & $0-22$ \\
\hline $\begin{array}{l}\text { Anticoagulation treatment } \\
\text { knowledge }\end{array}$ & 35.9 & 19.3 & 0-92 \\
\hline Warfarin $(n=53)$ & 33.5 & 20.6 & $0-90.9$ \\
\hline NOACs $(n=98)$ & 38.4 & 19.1 & $0-91.7$ \\
\hline $\begin{array}{l}\text { Satisfaction with services and } \\
\text { anticoagulation treatment }\end{array}$ & 19.1 & 3.2 & $7-24$ \\
\hline $\begin{array}{l}\text { Perceived benefits of } \\
\text { anticoagulation treatment }\end{array}$ & 20.1 & 2.5 & $13-25$ \\
\hline $\begin{array}{l}\text { Perceived barriers to } \\
\text { anticoagulation treatment }\end{array}$ & 1.1 & 1.3 & $0-6$ \\
\hline $\begin{array}{l}\text { Self-efficacy for anticoagulant } \\
\text { use }\end{array}$ & 32.9 & 6.1 & $18-39$ \\
\hline Anticoagulation adherence & 8.8 & 1.9 & $7-15$ \\
\hline
\end{tabular}

NOACs, novel oral anticoagulants. 
Table 2 Sample characteristics and comparisons of self-efficacy and anticoagulation adherence among different characteristics of patients with atrial fibrillation $(n=151)$

\begin{tabular}{|c|c|c|c|c|c|c|c|}
\hline \multirow[b]{2}{*}{ Variables } & \multirow[b]{2}{*}{$\mathbf{N}$} & \multicolumn{3}{|c|}{ Self-efficacy } & \multicolumn{3}{|c|}{ Adherence } \\
\hline & & $\mathrm{M} \pm \mathrm{SD}$ & $\mathbf{F} / \mathrm{t}$ & $P$ value & $\mathrm{M} \pm \mathrm{SD}$ & $\mathbf{F} / \mathrm{t}$ & $P$ value \\
\hline Gender & & & -1.56 & 0.121 & & 1.50 & 0.135 \\
\hline Female & 56 & $31.9 \pm 6.8$ & & & $9.1 \pm 2.1$ & & \\
\hline Male & 95 & $33.5 \pm 5.6$ & & & $8.7 \pm 1.7$ & & \\
\hline Educational level & & & 0.17 & 0.915 & & 0.37 & 0.779 \\
\hline Primary school and below & 51 & $32.9 \pm 6.2$ & & & $8.8 \pm 1.9$ & & \\
\hline Middle school & 21 & $33.5 \pm 7.1$ & & & $8.8 \pm 2.2$ & & \\
\hline High school & 33 & $33.1 \pm 5.8$ & & & $8.6 \pm 1.9$ & & \\
\hline College and above & 46 & $32.4 \pm 5.7$ & & & $9.0 \pm 1.7$ & & \\
\hline Marital status & & & 1.18 & 0.238 & & -0.52 & 0.604 \\
\hline Married & 125 & $32.6 \pm 5.9$ & & & $8.9 \pm 1.9$ & & \\
\hline Single, divorced or widowed & 26 & $34.2 \pm 6.9$ & & & $8.7 \pm 2.0$ & & \\
\hline Employment status & & & 0.54 & 0.584 & & 0.73 & 0.482 \\
\hline Full time, part-time & 29 & $32.9 \pm 6.5$ & & & $9.2 \pm 2.0$ & & \\
\hline Retired & 107 & $33.1 \pm 5.7$ & & & $8.7 \pm 1.8$ & & \\
\hline Unemployed & 15 & $31.3 \pm 7.6$ & & & $8.7 \pm 2.0$ & & \\
\hline $\mathrm{CHA}_{2} \mathrm{DS}_{2}-\mathrm{VAS}_{\mathrm{C}}$ & & & 0.18 & 0.86 & & -0.82 & 0.416 \\
\hline Low-middle risk & 9 & $33.2 \pm 6.1$ & & & $8.3 \pm 1.6$ & & \\
\hline High risk & 142 & $32.9 \pm 6.1$ & & & $8.9 \pm 1.9$ & & \\
\hline HAS-BLED & & & 0.92 & 0.360 & & -0.86 & 0.392 \\
\hline Low risk & 60 & $33.4 \pm 6.0$ & & & $8.7 \pm 1.8$ & & \\
\hline High risk & 91 & $32.5 \pm 6.14$ & & & $8.9 \pm 1.9$ & & \\
\hline Anticoagulants & & & 1.37 & 0.172 & & -0.99 & 0.324 \\
\hline Warfarin & 53 & $33.8 \pm 4.9$ & & & $8.6 \pm 1.6$ & & \\
\hline NOACs & 98 & $32.4 \pm 6.6$ & & & $8.9 \pm 2.0$ & & \\
\hline Dosing frequency & & & 0.08 & 0.922 & & 0.45 & 0.641 \\
\hline Once a day & 135 & $32.9 \pm 6.0$ & & & $8.8 \pm 1.9$ & & \\
\hline Twice a day & 11 & $33.5 \pm 6.9$ & & & $9.3 \pm 1.6$ & & \\
\hline Once every 2 days & 5 & $32.2 \pm 7.1$ & & & $8.4 \pm 1.4$ & & \\
\hline Number of adverse reactions & & & 1.18 & 0.320 & & -2.15 & 0.096 \\
\hline None & 77 & $33.4 \pm 5.7$ & & & $8.7 \pm 1.8$ & & \\
\hline One & 51 & $33.0 \pm 6.3$ & & & $8.8 \pm 1.7$ & & \\
\hline Two & 14 & $30.9 \pm 6.7$ & & & $8.7 \pm 1.9$ & & \\
\hline Three and more & 9 & $30.4 \pm 7.0$ & & & $10.3 \pm 2.5$ & & \\
\hline
\end{tabular}

$\mathrm{F}$, the value of one-way analysis of variables; NOACs, novel oral anticoagulants; the value of dependent t-test.

The subjects were asked to indicate all concerns that apply to them. Each concern was scored 1 . The potential scores range from 0 to 10 , with higher scores indicating more concerns. The scale has shown acceptable psychometric properties in a previous study involving patients treated with anticoagulants. ${ }^{22}$

The Self-efficacy for Appropriate Medication Use scale (SEAMS) ${ }^{23}$ was used to measure self-efficacy for appropriate anticoagulant use. The 13-item scale covers two dimensions of self-efficacy: for taking medications under difficult circumstances and for taking medications under uncertain or changing circumstances. For each item, the subjects indicated their level of confidence about taking medications correctly under a specific circumstance on a three-point response scale (1-not confident, 2-somewhat confident, and 3-very confident). The potential scores range from 13 to 39, with high scores indicating higher levels of self-efficacy for appropriate anticoagulant use. The SEAMS has shown good psychometric properties for patients with coronary heart disease and other 
comorbid conditions. ${ }^{23}$ The scale was translated into Chinese by our research team with a CVI 1.0 and Cronbach's $\alpha 0.93$.

The short-form Adherence to Refills and Medications Scale (ARMS) ${ }^{24}$ was used to measure adherence to anticoagulation treatment. There are seven items on the scale. Subjects were asked to indicate how often they actually miss taking their anticoagulants in each item on a 4-point Likert scale (1-none of the time to 4-all of the time). The total score of the seven items represents the scale score, with a possible range of 7-28. A higher score indicates worse adherence to anticoagulation treatment. The scale has shown good psychometric properties for patients with coronary heart diseases $(n=435){ }^{24}$ The scale correlated strongly both with the Morisky adherence scale $^{25}$ (Spearman's rho $=-0.598, \mathrm{p}<0.01$ ) and the cumulative medication gap $^{26}$ during the previous 6 months (Spearman's rho $=0.339, \mathrm{p}<0.01$ ) ${ }^{24}$ Patients with low ARMS scores were significantly more likely to have controlled blood pressure $(81.3 \%$ vs $73.2 \%, \mathrm{p}<0.05)$. The scale also had good internal consistency (Cronbach's $\alpha=0.814$ ) and test-retest reliability (Spearman's rho $=0.693, \mathrm{p}<0.001) .{ }^{24}$ In this study, Cronbach's $\alpha$ was 0.70 .

\section{Statistical methods}

Data were analysed using the Statistical Package for Social Sciences V.20.0 (SPSS). Descriptive analyses were used to describe study variables. Independent t-tests and one-way analysis of variance were performed to analyse the differences in anticoagulation adherence scores among different categorical study variables. Pearson product-moment correlations were performed to analyse the correlations among the continuous variables. Due to a large number of potential explanatory variables, stepwise linear regression was chosen for statistical model selection. All study variables were entered as dependent variables into stepwise linear regression models to find significant influencing factors of anticoagulant adherence. These included demographics (age, gender, educational level, marital status and employment status), clinical variables (disease duration, $\mathrm{CHA}_{2} \mathrm{DS}_{2}-$ VASc score, HAS-BLED score, anticoagulants, dosing frequency and adverse reactions), symptom severity, anticoagulation treatment knowledge, satisfaction with services, perceived benefits, perceived barriers and self-efficacy for appropriate anticoagulant use. Categorical variables were dummy coded prior to analysis. The probability-of-F-to-enter $\leq 0.05$ was used as the criterion for entering a variable into the model; the probability-of-F-to-remove $\geq 0.10$ was used as the criterion for removing a variable from the model. Standardised residual plots and collinearity statistics of variance inflation factor were used to examine the normality and independent assumptions of the regression. There was no violation in both assumptions.

\section{RESULTS}

One of the researchers approached 156 eligible patients; 6 of them declined to participate. This left 151 eligible 


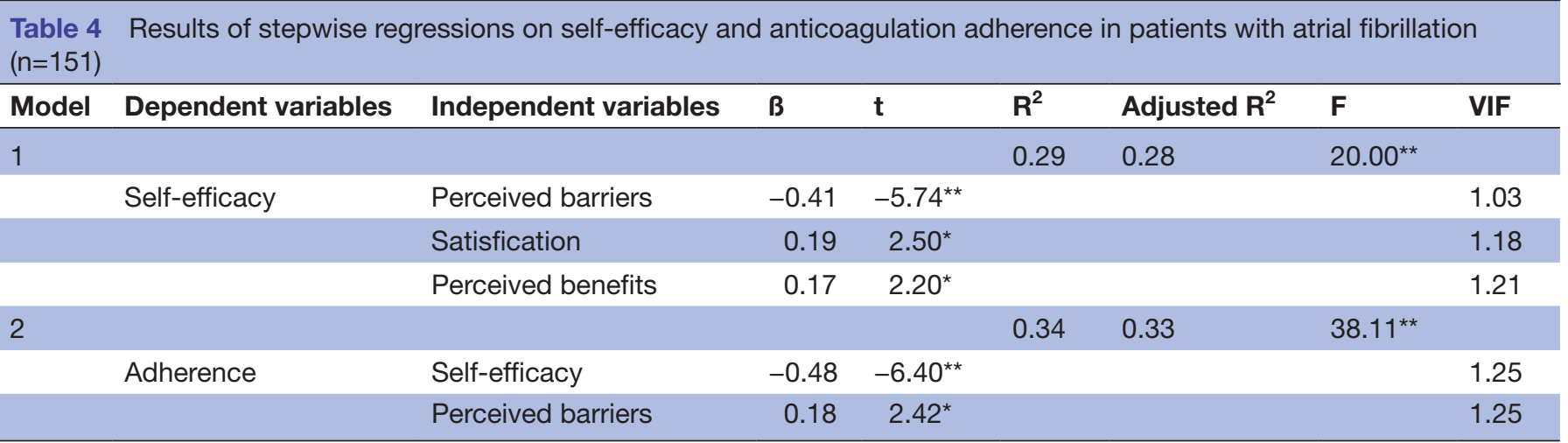

${ }^{*} \mathrm{P}<0.05 ;{ }^{* *} \mathrm{P}<0.001$. Adjusted $\mathrm{R}^{2}$ a modified version of $\mathrm{R}^{2}$ for the number of predictors in a model.

patients to take part in the study. All of them completed the study questionnaires, and their data were included in the final analysis. Every subject filled out all the questionnaires except the knowledge scale. Fifty-three $(35.1 \%)$ subjects receiving warfarin answered The Knowledge of Warfarin Anticoagulation Treatment Scale; 98 (64.9\%) subjects receiving NOACs filled out The Knowledge of NOACs Treatment Scale.

These subjects were recruited from clinics associated with two hospitals, with 93 and 58 subjects from each hospital, respectively. There was no significant difference in demographics or values of study variables between subjects recruited from the different hospitals (data not shown). The average age of the subjects was $72.0(\mathrm{SD}=8.6)$ (table 1). There were 95 men and 56 women in the study. The majority of the subjects were married $(n=125)$ and retired $(\mathrm{n}=107)$ (table 2). Subjects were diagnosed with an $\mathrm{AF}$ for 74.0 months $(\mathrm{SD}=61.1$ ) on average (table 1). Of the 151 subjects, 98 received NOACs and 53 received warfarin. Most subjects $(n=77)$ did not experience anticoagulation-related side effects (table 2).

The subjects reported an average score of $8.8(\mathrm{SD}=1.9)$ on ARMS. The average score on the symptom subscale of the AFSS was $6.8(\mathrm{SD}=5.4)$. Shortness of breath during physical activity was the most common symptom experienced by these subjects. The subjects had a mean score of $35.9(\mathrm{SD}=19.3)$ on the anticoagulation treatment knowledge scale. Most subjects miss more than half of the treatment-related questions, with most mistakes made in

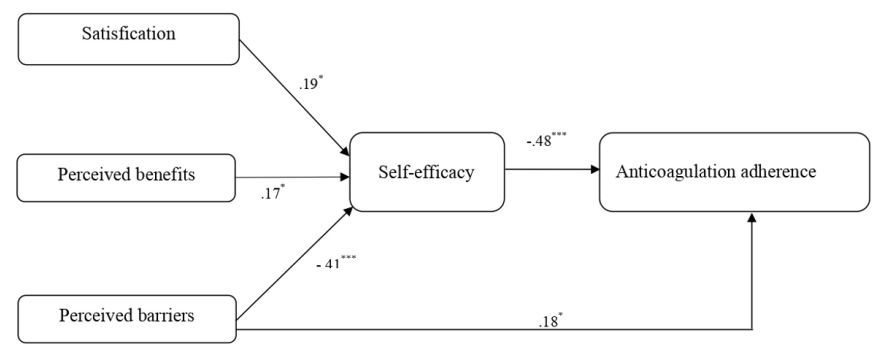

Figure 1 Relationships among symptom severity, satisfaction, perceived benefits and perceived barriers in selfefficacy and adherence to anticoagulation therapy. ${ }^{*} \mathrm{P}<0.05$; ${ }^{* \star *} \mathrm{P}<0.001$. drug-food interactions, INR values, the timing of taking anticoagulants and how to prevent bleeding risks. They reported a mean score of $19.1 \quad(\mathrm{SD}=3.2)$ on the SSWT. Their average score on the perceived benefits subscale of the BAAS was $20.1(\mathrm{SD}=2.5)$. They reported an average score of $1.1(\mathrm{SD}=1.3)$ on the concerns about anticoagulation therapy scale. The top three concerns indicated by the subjects were: (1) side effects $(\mathrm{n}=53)$; (2) drug interactions $(\mathrm{n}=44)$ and (3) forgetting to take anticoagulants $(\mathrm{n}=33)$. The subjects had a mean score of $32.9(\mathrm{SD}=6.1)$ on the SEAMS.

The difference in medication adherence between warfarin (mean=8.6; $\mathrm{SD}=1.6$ ) and NOACs (mean=8.9; $\mathrm{SD}=2.0$ ) was statistically insignificant. There was also no significant difference both in anticoagulant adherence and self-efficacy among subjects with different demographics and clinical variables $\left(\mathrm{CHA}_{2} \mathrm{DS}_{2}-\mathrm{VASc}\right.$ score, HAS-BLED score, anticoagulants, dosing frequency and adverse reactions) (table 2). Results of Pearson correlation analyses showed that anticoagulation adherence was significantly associated with perceived barriers to $(r=0.40$, $\mathrm{p}<0.001)$ and self-efficacy for appropriate anticoagulant use $(\mathrm{r}=-0.56, \mathrm{p}<0.001)$. Other study variables (age, disease duration, symptom severity, knowledge, satisfaction and perceived benefits) were not significantly associated with anticoagulation adherence (table 3). The self-efficacy for anticoagulant use was significantly associated with symptom severity $(\mathrm{r}=-0.23, \mathrm{p}=0.02)$, satisfaction $(\mathrm{r}=0.29, \mathrm{p}<0.001)$, perceived benefits $(\mathrm{r}=0.31, \mathrm{p}<0.001)$ and perceived barriers $(\mathrm{r}=-0.45, \mathrm{p}<0.001)$. Age, disease duration and knowledge were not related to self-efficacy.

Results of stepwise linear regression analyses showed that perceived barriers $(\beta=0.18, p=0.017)$ and self-efficacy $(\beta=-0.48, p<0.001)$ were significant predictors of adherence to anticoagulation therapy. For every 1-unit increase in the perceived barriers score, there will be a 0.18-unit increase in the adherence to anticoagulation therapy score. In addition, for every 1-unit increase in the self-efficacy score, there will be a 0.48 -unit decrease in the adherence to anticoagulation therapy score. Perceived barriers and self-efficacy collectively explained $34.0 \%$ of the variance in adherence to anticoagulation therapy 
$\left(\mathrm{F}_{(2,149)}=38.1, \mathrm{p}<0.001\right)$ (see table 4). Other variables were excluded from the model. As for self-efficacy, the satisfaction with services, perceived benefits and perceived barriers were the significant predictors. These three variables together explained $29.0 \%$ of the variance in self-efficacy for anticoagulant use $\left(\mathrm{F}_{(3,148)}=20.0, \mathrm{p}<0.001\right)$ (see table 4). Figure 1 presents the relationships among perceived benefits, perceived barriers, self-efficacy and adherence to anticoagulation therapy with their respective standardised regression coefficients $(\beta)$.

\section{DISCUSSION}

This is one of the few studies that compared differences in medication adherence between warfarin and NOACs among patients with AF. We found no better adherence to NOACs compared with warfarin. It is difficult to compare our findings with other studies because most studies included only patients treated with warfarin ${ }^{27}$ and used different adherence measures. ${ }^{27}$ Nevertheless, our study subjects reported relatively good adherence to anticoagulant therapy with an average score of $8.8(\mathrm{SD}=1.9)$ out of the possible range 7-28 in ARMS, compared with 32.3\% of non-adherent to warfarin therapy in a cross-sectional survey of 288 patients with $\mathrm{AF}^{27}$

Perceived barriers and self-efficacy were found to be significant predictors of medication adherence. Consistent with findings in previous studies of other populations, ${ }^{28}{ }^{29}$ patients with greater self-efficacy and perceived fewer barriers reported better adherence to anticoagulation therapy. When considering the pharmacokinetics of these anticoagulants, the effect of the adherence on clinical outcomes may be different. It may be better to show their results separately. Therefore, we further analysed warfarin and NOACs users separately and found that the independent predictors of perceived barriers and self-efficacy for adherence were persistent. Concerns about side effects, drug interactions and forgetting to take anticoagulants were the top barriers to appropriate anticoagulant use. ${ }^{27}$ Symptom severity, satisfaction, perceived benefits and perceived barriers were significant predictors of self-efficacy for appropriate anticoagulant use. Patients with severer symptoms, lower satisfaction, perceived less benefit and perceived greater barriers reported lower self-efficacy for appropriate anticoagulant use. Addressing AF-related symptoms, satisfaction with services, perceived benefits and barriers of taking anticoagulants may help increase self-efficacy and lead to enhanced anticoagulation adherence.

Different from findings in previous studies, ${ }^{25} 26$ we found that medication adherence was not significantly related to anticoagulation treatment knowledge. This may be because most of these studies were conducted in different countries and only focused on patients treated with warfarin. Although our subjects showed poor understating of anticoagulation treatment, they reported good adherence to anticoagulation treatment. This may be partially explained by the Taiwanese culture of obedience to a physician's orders. The treatment knowledge scores were low in both warfarin and NOACs treatment groups, indicating the need for strengthening anticoagulation treatment patient education. Special attention should be paid to treatment-related issues, such as drug-food interactions, INR values, the timing of taking anticoagulants and how to prevent bleeding risks. These are areas that most of our subjects answered incorrectly.

This study had several limitations. First, the subjects were recruited from cardiology clinics of two teaching hospitals and may vary from those seen in other clinical settings. Thus, the results may not be generalisable outside this sample. Second, the cross-sectional nature of the study precluded an assessment of medication adherence change over time and did not permit us to determine causal relationships among the study variables. Third, a self-report questionnaire was used to measure medication adherence, which was subject to recall and social desirability biases. Finally, the influences of anticoagulation adherence on patients' treatment outcomes were not examined. Replication of the findings with longitudinal study design, objective measures of medication adherence and clinical outcome measures are warranted. Nevertheless, the study results showed no better adherence to NOACs compared with warfarin and present evidence for the importance of perceived barriers and self-efficacyon the adherence to anticoagulation therapy in patients with AF. Strategies to address perceived barriers and self-efficacy may be more likely to be translated to other population groups, as the influence of these factors on medication adherence has also been reported in studies with other populations. ${ }^{28} 29$

Acknowledgements The authors thank all the patients participated in this study.

Contributors All authors listed have read the manuscript, approved the validity and legitimacy of the data and its interpretation, and agree to the submission of the manuscript to the BMJ Open. All authors adhere to the ICMJE expectations for authorship and the specific contributions of each author to the manuscript are as following: 1. P-TC: conception and design, acquisition of data, analysis and interpretation of data revising the manuscript critically. 2. T-JW: conception and design, analysis and interpretation of data, drafting and revising the manuscript. 3. $\mathrm{M}-\mathrm{HH}$ : conception and design, acquisition of data, analysis and interpretation of data revising the manuscript critically. 4. J-CL: acquisition of data, analysis and interpretation of data. 5.C-YL: conception and design, analysis and interpretation of data and revising the manuscript critically. 6. K-YW and W-CL: conception and design and revising the manuscript critically.

Funding This work was supported by the Ministry of Science and Technology, Taiwan, ROC [grant number: MOST 107-2314-B-227-001-MY2]; and the Cardinal Tien Junior College of Healthcare and Management [grant number: CTCN-105-07]. Competing interests None declared.

Patient consent for publication Not required.

Ethics approval Institutional Review Board approvals were obtained from the Taipei Medical University (TMU-JIRB No. 201505054).

Provenance and peer review Not commissioned; externally peer reviewed.

Data availability statement Data are available upon reasonable request. No data are available. All data relevant to the study are included in the article or uploaded as supplementary information.

Open access This is an open access article distributed in accordance with the Creative Commons Attribution Non Commercial (CC BY-NC 4.0) license, which permits others to distribute, remix, adapt, build upon this work non-commercially, 
and license their derivative works on different terms, provided the original work is properly cited, appropriate credit is given, any changes made indicated, and the use is non-commercial. See: http://creativecommons.org/licenses/by-nc/4.0/.

\section{REFERENCES}

1. Chiang CE, TJ W, Ueng KC, et al. Guidelines of the Taiwan heart rhythm Society and the Taiwan Society of cardiology for the management of atrial fibrillation. J Formos Med Assoc 2016;2016:893-952.

2. January CT, Wann LS, Alpert JS, et al. AHAVACC/HRS guideline for the management of patients with atrial fibrillation: a report of the American College of cardiology/American heart association Task force on practice guidelines and the heart rhythm Society. J Am Coll Cardiol 2014;2014:e1-76.

3. Kirchhof P, Benussi S, Kotecha D, et al. Esc guidelines for the management of atrial fibrillation developed in collaboration with EACTS. EP Europace 2016;2016:1609-78.

4. Kishore A, Vail A, Majid A, et al. Detection of atrial fibrillation after ischemic stroke or transient ischemic attack: a systematic review and meta-analysis. Stroke 2014;45:520-6.

5. Taiwan Heart Rhythm Society. The current situation cur and complications of atrial fibrillation in Taiwan, 2015. Available: http:// thrs.org.tw/people/content.asp?id=10 [Accessed 1 May 2017].

6. Yu H-C, Tsai Y-F, Chen M-C, et al. Underuse of antithrombotic therapy caused high incidence of ischemic stroke in patients with atrial fibrillation. Int J Stroke 2012;7:112-7.

7. Gamra H, Murin J, Chiang C-E, et al. Use of antithrombotics in atrial fibrillation in Africa, Europe, Asia and South America: insights from the International RealiseAF survey. Arch Cardiovasc Dis 2014;107:77-87.

8. Mozaffarian D, Benjamin EJ, Go AS, et al. Heart disease and stroke statistics-2016 update: a report from the American heart association. Circulation 2016;133:e38-60.

9. Hsieh FI, Lien LM, Chen ST, et al. Get with the Guidelines-Stroke performance indicators: surveillance of stroke care in the Taiwan stroke Registry: get with the Guidelines-Stroke in Taiwan. Circulation 2010;122:1116-23.

10. Chao T-F, Liu C-J, Wang K-L, et al. Using the CHA2DS2-VASc Score for Refining Stroke Risk Stratification in 'Low-Risk' Asian Patients With Atrial Fibrillation. J Am Coll Cardiol 2014;64:1658-65.

11. Lin SY, Chen YW, Kang HC, et al. Warfarin dosing algorithm: specific Inr goal for Asian population. Formosa J Clin Pharm 2015;23:189-202.

12. Shore S, Carey EP, Turakhia MP, et al. Adherence to dabigatran therapy and longitudinal patient outcomes: insights from the Veterans health administration. Am Heart J 2014;167:810-7.

13. Brown TM, Siu K, Walker D, et al. Development of a conceptual model of adherence to oral anticoagulants to reduce risk of stroke in patients with atrial fibrillation. JMCP 2012;18:351-62.
14. O'Brien EC, Simon DN, Allen LA, et al. Reasons for warfarin discontinuation in the outcomes Registry for better informed treatment of atrial fibrillation (ORBIT-AF). Am Heart $J$ 2014:168:487-94.

15. Yao X, Abraham NS, Alexander GC, et al. Effect of adherence to oral anticoagulants on risk of stroke and major bleeding among patients with atrial fibrillation. J Am Heart Assoc 2016;5:1-13.

16. Choi JC, Dibonaventura MD, Kopenhafer L, et al. Survey of the use of warfarin and the newer anticoagulant dabigatran in patients with atrial fibrillation. Patient Prefer Adherence 2014;8:167-77.

17. Maglio C, Sra J, Paquette M, et al. Measuring quality of life and symptom severity in patients with atrial fibrillation. Pacing Clin Electrophysiol 1998;21.

18. Dorian P, Burk C, Mullin CM, et al. Interpreting changes in quality of life in atrial fibrillation: how much change is meaningful? Am Heart $J$ 2013;166:381-7.

19. Waltz CF, Strickland O, Lenz ER. Measurement in Nursing and Health Research. New York, NY: Springer Publishing Company, 2010.

20. DeVellis RF. Scale development: theory and applications. Los Angeles, CA: Sage, 2012: 109-10.

21. Wang Y, Kong MC, Lee LH, et al. Knowledge, satisfaction, and concerns regarding warfarin therapy and their association with warfarin adherence and anticoagulation control. Thromb Res 2014;133:550-4.

22. Orensky IA, Holdford DA. Predictors of noncompliance with warfarin therapy in an outpatient anticoagulation clinic. Pharmacotherapy 2005;25:1801-8.

23. Risser J, Jacobson TA, Kripalani S. Development and psychometric evaluation of the self-efficacy for appropriate medication use scale (SEAMS) in low-literacy patients with chronic disease. J Nurs Meas 2007;15:203-19.

24. Kripalani S, Risser J, Gatti ME, et al. Development and evaluation of the adherence to Refills and medications scale (arms) among low-literacy patients with chronic disease. Value Health 2009:12:118-23.

25. Morisky DE, Green LW, Levine DM. Concurrent and predictive validity of a self-reported measure of medication adherence. Med Care 1986;24:67-74.

26. Gazmararian J, Kripalani S, Miller MJ, et al. Factors associated with medication refill adherence in cardiovascular-related diseases: a focus on health literacy. J GenIntern Med 2006;21:1215-21.

27. Zhao $\mathrm{S}$, Zhao $\mathrm{H}$, Wang $\mathrm{X}$, et al. Factors influencing medication knowledge and beliefs on warfarin adherence among patients with atrial fibrillation in China. Patient Prefer Adherence 2017;11:213-20.

28. Di Minno A, Spadarella G, Tufano A, et al. Ensuring medication adherence with direct oral anticoagulant drugs: lessons from adherence with vitamin K antagonists (VKAs). Thromb Res 2014;133:699-704.

29. Mishra SI, Gioia D, Childress S, et al. Adherence to medication regimens among low-income patients with multiple comorbid chronic conditions. Health Soc Work 2011;36:249-58. 